OPEN ACCESS

Edited by:

Alberto Mas,

University Rovira i Virgill, Spain

Reviewed by:

Maurizio Ciani,

Università Politecnica delle Marche,

Italy

Blondin Bruno,

SupAgro, France

*Correspondence:

Amparo Quero

aquero/@iata.csic.es

${ }^{\dagger}$ Present Address:

Bruno M. Oliveira,

Centro Multidisciplinar de Luís

Eduardo Magalhães, UFOB -

Universidade Federal do Oeste da

Bahia, Barreiras, Brazil

Specialty section

This article was submitted to

Food Microbiology,

a section of the journal

Frontiers in Microbiology

Received: 10 February 2016 Accepted: 17 March 2016

Published: 31 March 2016

Citation:

Pérez-Torrado R, Oliveira BM,

Zemančiková J, Sychrová H and Querol A (2016) Alternative Glycerol

Balance Strategies among Saccharomyces Species in Response to Winemaking Stress.

Front. Microbiol. 7:435

doi: 10.3389/fmicb.2016.00435

\section{Alternative Glycerol Balance Strategies among Saccharomyces Species in Response to Winemaking Stress}

\author{
Roberto Pérez-Torrado ${ }^{1}$, Bruno M. Oliveira ${ }^{1+}$, Jana Zemančíková ${ }^{2}$, Hana Sychrová $^{2}$ and \\ Amparo Querol ${ }^{1 *}$
}

${ }^{1}$ Food Biotechnology Department, Systems Biology in Yeast of Biotechnological Interest, Instituto de Agroquímica y Tecnología de los Alimentos, IATA-CSIC, Valencia, Spain, ${ }^{2}$ Department of Membrane Transport, Institute of Physiology, CAS, Prague, Czech Republic

Production and balance of glycerol is essential for the survival of yeast cells in certain stressful conditions as hyperosmotic or cold shock that occur during industrial processes as winemaking. These stress responses are well-known in S. cerevisiae, however, little is known in other phylogenetically close related Saccharomyces species associated with natural or fermentation environments such as S. uvarum, S. paradoxus or S. kudriavzevii. In this work we have investigated the expression of four genes (GPD1, GPD2, STL1, and FPS1) crucial in the glycerol pool balance in the four species with a biotechnological potential (S. cerevisiae; S. paradoxus; S. uvarum; and S. kudriavzevii), and the ability of strains to grow under osmotic and cold stresses. The results show different pattern and level of expression among the different species, especially for STL1. We also studied the function of Stl1 glycerol symporter in the survival to osmotic changes and cell growth capacity in winemaking environments. These experiments also revealed a different functionality of the glycerol transporters among the different species studied. All these data point to different strategies to handle glycerol accumulation in response to winemaking stresses as hyperosmotic or cold-hyperosmotic stress in the different species, with variable emphasis in the production, influx, or efflux of glycerol.

Keywords: glycerol, yeast, Saccharomyces, stress, winemaking

\section{INTRODUCTION}

In the fermentation industry, especially winemaking, the resistance to osmotic stress and the ability to grow at low temperatures are required features for yeast strains (Pretorius et al., 2012). It is known that $S$. cerevisiae seeks to increase intracellular glycerol content when subjected to osmotic stress or cold in vinification or standard laboratory growth conditions (Panadero et al., 2006; Petelenz-Kurdziel et al., 2013; Oliveira et al., 2014). This intracellular accumulation is very important for osmotic equilibrium during the first phase of fermentation and to act as key cryoprotector agent for adaptation to cold environments allowing cellular viability with

Abbreviations: GPD1, glycerol-3-phosphate dehydrogenase 1 gene; GPD2, glycerol-3-phosphate dehydrogenase 2 gene; STL1, glycerol proton symporter gene; FPS1, glycerol channel gene; ACT1, actin gene; RDN18-1, 18S ribosomal RNA gene; qRT-PCR, quantitative real-time PCR; dithiothreitol, DTT. 
implications in the fermentation yield (Remize et al., 2001; Tulha et al., 2010). A rapid and specific activation of the gene expression have been identified as an essential mechanism in the $S$. cerevisiae cells to respond to acute stresses, such as those associated with the different industrial fermentation processes (de Nadal et al., 2011). However, little is known about these stress responses in other Saccharomyces species associated with natural or fermentation environments such as S. uvarum (Naumov et al., 2002; Rementeria et al., 2003; Demuyter et al., 2004), S. paradoxus, isolated from Croatian vineyards (Redzepovic et al., 2002) or natural yeast hybrids between species of the genus Saccharomyces such as $S$. cerevisiae $\times S$. kudriavzevii (Gonzalez et al., 2007) and S. cerevisiae $\times$ S. uvarum (Le Jeune et al., 2007; Pérez-Torrado et al., 2015) which may participate in the fermentative processes. S. uvarum and S. kudriavzevii present important physiological traits like the ability to grow at lower temperatures and produce more glycerol than S. cerevisiae (Gonzalez et al., 2007; Gamero et al., 2013; Oliveira et al., 2014). However, S. paradoxus, besides being a widely distributed yeast species mainly associated with natural environments and not very relevant in fermentations, is physiologically more similar to $S$. cerevisiae (Tronchoni et al., 2009).

It is well-known that S. cerevisiae and other yeast species are capable to modulate the glycerol synthesis and its intracellular content in accordance with environmental osmotic changes (Hohmann et al., 2007; Hubmann et al., 2011). They can also control an active glycerol import from the extracellular medium in symport with protons via Stll transporter (Tulha et al., 2010; Dušková et al., 2015a). Besides its important role in osmoregulation, the Stll function is directly related to cell survival and adaptation to cold stress in S. cerevisiae strains (Tulha et al., 2010). The yeast cells may also regulate their glycerol content by controlling its efflux via the Fps1 channel (Luyten et al., 1995). This channel can be quickly closed avoiding the glycerol efflux, and thus contributing to an efficient osmoregulation with direct implications on increasing the fermentation yield (Wei et al., 2013).

The understanding of the phylogenetic and physiological relationships between $S$. cerevisiae and other Saccharomyces species, as well as main ecological, environmental, and human factors that have driven the emergence of phenotypic changes among species of Saccharomyces genus, have been cleared in many works (Landry et al., 2006; Peris et al., 2014). Several studies have focused in understanding the cryophilic character of $S$. uvarum and specially $S$. kudriavzevii at the molecular level, including transcriptomic and metabolomic studies (Combina et al., 2012; López-Malo et al., 2013). Some aspects of $S$. kudriavzevii have been highlighted in relation to cold resistance and winemaking as membrane composition (Tronchoni et al., 2012), or translation efficiency (Tronchoni et al., 2014). However, little information about these species and the glycerol synthesis is available. In the case of S. kudriavzevii, the increased cold tolerance has been related to elevated glycerol synthesis as a consequence of increased expression and activity of Gpdlp in winemaking conditions (Oliveira et al., 2014). For this reason a better understanding of Saccharomyces species physiological and
TABLE 1 | Strains used in this study.

\begin{tabular}{|c|c|c|}
\hline Strain & Species & Description \\
\hline $\mathrm{T} 3^{\mathrm{a}}$ & S. cerevisiae & Wine strain, Alicante, Spain \\
\hline FCry & S. cerevisiae & Wine strain, commercial (AEB), France \\
\hline Chr 16.2 & S. paradoxus & Wild strain, Oak bark, Hungary \\
\hline 108 & S. paradoxus & Wild strain, Croatia \\
\hline BMV58 & S. uvarum & Wine, Spain \\
\hline $12600^{a}$ & S. uvarum & Sweet wine, Spain \\
\hline CR85 & S. kudriavzevii & Wild strain, Oak bark, Spain \\
\hline IFO1802 ${ }^{\mathrm{b}}$ & S. kudriavzevii & Type strain, Soil, Japan \\
\hline BY4741hog1 $\Delta s t 11 \Delta$ & S. cerevisiae & Lab strain (Dušková et al., 2015b) \\
\hline BY-hs-YEp352 & S. cerevisiae & $\begin{array}{l}\text { BY4741hog1 } \Delta \text { st/1 } \Delta \text { YEp352 (This } \\
\text { work) }\end{array}$ \\
\hline BY-hs-pSTL1-T73 & S. cerevisiae & $\begin{array}{l}\text { BY4741hog1 } \Delta \text { st/1 } \Delta \text { YEp352- } \\
\text { STL1T73(This } \\
\text { work) }\end{array}$ \\
\hline BY-hs-pSTL1-BMV58 & S. cerevisiae & $\begin{array}{l}\text { BY4741hog1 } \Delta \text { st1 } \triangle \text { YEp352- } \\
\text { STL1 BMV58(This } \\
\text { work) }\end{array}$ \\
\hline BY-hs-pSTL1-IFO1802 & S. cerevisiae & $\begin{array}{l}\text { BY4741hog1 } \Delta \text { st/1 } \Delta \text { YEp352- } \\
\text { STL1 }{ }_{\text {IFO1802 }} \text { (This } \\
\text { work) }\end{array}$ \\
\hline
\end{tabular}

Some strains are available from collections.

${ }^{a} C E C T$; ${ }^{b} N B R C$.

molecular features with potential biotechnological interest is needed.

Hence, in this work we decided to investigate the expression of genes crucial to the balance of glycerol (GPD1, GPD2, STL1, and FPS1) in two yeast strains of each of the four species with a biotechnological potential (S. cerevisiae; S. paradoxus; S. uvarum; and $S$. kudriavzevii). We also studied the function of Stl1 glycerol symporter, in the survival to osmotic changes and cell growth capacity in winemaking environments.

\section{METHODS}

\section{Yeast Strains and Growth Conditions}

Yeast strains origin, availability are described in Table 1. Two different strains of each species were studied. For S. cerevisiae, T73 model wine strain (Querol et al., 1994; Lopes et al., 2010) and the commercial wine strain Fermol Cryophile FCry (AEB Group); selected as adapted to low temperature (Gamero et al., 2013) were chosen. The 108 and Chr 16.2 strains isolated from natural environment were used as representatives of $S$. paradoxus. For S. uvarum, the 12600 and BMV58 strains isolated from wine in Spain were studied. BMV58 was commercialized (Lallemand Inc) because of its high glycerol production and good fermentative properties (patent ES2330709 B1). For $S$. kudriavzevii species, IFO1802 (type strain), and the CR85 wild strain isolated in Spain (Dušková et al., 2015b) were used. The S. cerevisiae BY4741 $\Delta$ hog $1 \Delta$ stll (Pérez-Torrado et al., 2009) was used as a laboratory strain for the expression of STL1 genes and comparison of the function of their products under hyperosmotic-stress conditions. 
Yeast cells were maintained and grown in YPD medium (2\% glucose, $2 \%$ Bacto peptone, and 1\% Yeast extract) or SCUra medium (YNB 0.67\%, glucose 2\%, Drop-out -Ura $1.92 \mathrm{~g} / \mathrm{l}$ (Formedium)) at $28^{\circ} \mathrm{C}$ for the $S$. cerevisiae and $S$. paradoxus species and $25^{\circ} \mathrm{C}$ for $S$. kudriavzevii and $S$. uvarum species.

The wine fermentations were performed in $250 \mathrm{ml}$ bottles filled with $200 \mathrm{ml}$ of MS300 synthetic must ( $100 \mathrm{~g} / \mathrm{L}$ glucose, $100 \mathrm{~g} / \mathrm{L}$ fructose, $6 \mathrm{~g} / \mathrm{L}$ citric acid, $6 \mathrm{~g} / \mathrm{L}$ malic acid, mineral salts, vitamins, anaerobic growth factors, $300 \mathrm{mg} / \mathrm{L}$ assimilable nitrogen) simulating standard grape juice (Bely et al., 2003) at $12^{\circ} \mathrm{C}$ with agitation $(150 \mathrm{rpm})$ in triplicate. Overnight precultures were inoculated at $5.0 \times 10^{6}$ cells $/ \mathrm{ml}$ density determined by measuring $\mathrm{OD}_{600}$. To study the expression of genes related to glycerol balance under hyperosmotic stress, the cells from exponentially growing precultures were washed with water and transferred to YP (2\% Bacto peptone and $1 \%$ yeast extract) with $2 \%$ glucose or $2 \%$ mannitol as a source of carbon, to the same medium supplemented with $1 \mathrm{M}$ sorbitol (hyperosmotic stress), which is not assimilable for any of the species studied, or to $\mathrm{H}_{2} \mathrm{O}$ (hypoosmotic stress). This experiment was performed in 21 flasks filled with $400 \mathrm{ml}$ of media in triplicate at $25^{\circ} \mathrm{C}$ and $150 \mathrm{rpm}$.

The tolerance to hyperosmotic stress was evaluated by drop tests. Yeasts were grown overnight in YPD or SC-ura medium, then cultures were diluted to $\mathrm{OD}_{600}=0.2$ and cells were allowed to grow in the same media until $\mathrm{OD}_{600}=1$. Then, serial dilutions of cells were transferred to plates with YPD; YPD + $0.8 \mathrm{M} \mathrm{NaCl}$; YPD $+1.25 \mathrm{M} \mathrm{KCl}$, incubated at 12 and $25^{\circ} \mathrm{C}$ and evaluated each day. The growth of Saccharomyces species was also compared in plates with SC containing $2 \mathrm{M}$ sorbitol or $2 \mathrm{M} \mathrm{KCl}$ and supplemented or not with $1 \mathrm{mM}$ glycerol. To investigate the functional differences of Stl1, the growth of BY4741 $\Delta$ hog $1 \Delta$ stl1 cells transformed with appropriate plasmids was monitored on plates with SC-ura containing $0.7 \mathrm{M}$ sorbitol, which or $0.3 \mathrm{M}$ $\mathrm{KCl}$ and with or without $10 \mathrm{mM}$ glycerol. Experiments were performed in triplicate, representative results are shown.

For the intracellular glycerol measurements, cells were grown in $250 \mathrm{ml}$ flasks with SC-ura with $10 \%$ of glucose at $28^{\circ} \mathrm{C}$ with agitation $(150 \mathrm{rpm})$ in triplicate until the glucose concentration achieved $<2 \mathrm{~g} / \mathrm{l}$.

\section{Plasmid Construction}

Plasmids expressing the S. cerevisiae T73, S. bayanus BMV58, and S. kudriavzevii IFO1802 STL1 genes under NHA1 gene promoter were constructed by exchanging the NHA1 coding sequence in pNHA1-985 (YEp352 derivative, Kinclová et al., 2001) by homologous recombination. All constructions were confirmed by diagnostic PCR and sequencing. The primers, listed in Table 2, were designed based on data from Saccharomyces Genome Database (Cherry et al., 2012) and used to amplify the DNA fragments (from genomic DNAs) with suitable flanking regions for homologous recombination and confirmation.

\section{Analytical Determinations}

The extracellular glycerol concentrations and residual sugars (glucose and fructose) were determined in must and medium samples by HPLC (Thermo Fisher Scientific, Waltham, MA) equipped with a refraction index detector. The column employed was a HyperREZTM XP Carbohydrate $\mathrm{H}+8 \mu \mathrm{m}$ (Thermo Fisher Scientific) and the conditions used in the analysis were as follows: eluent, $1.5 \mathrm{mM} \mathrm{H}_{2} \mathrm{SO}_{4}$; flux, $0.6 \mathrm{ml} / \mathrm{min}$; and oven temperature, $50^{\circ} \mathrm{C}$. The samples were diluted, filtered through a $0.22-\mu \mathrm{m}$ nylon filter (Symta, Madrid, Spain) and injected in duplicate.

To determine intracellular glycerol content, $5 \mathrm{OD}_{600}$ units were harvested by filtration and quickly washed with $5 \mathrm{ml}$ of water and transferred to a tube containing $1 \mathrm{ml}$ of cold water. After no more than $20 \mathrm{~s}$ after sampling, the yeast suspension was boiled for $10 \mathrm{~min}$, cooled on ice, and centrifuged at 15,300 $\times$ $\mathrm{g}$ for $10 \mathrm{~min}\left(4^{\circ} \mathrm{C}\right)$. The supernatant was collected, filtered and directly analyzed by HPLC. A second sample ( $5 \mathrm{OD}_{600}$ units) was harvested by filtration in cellulose membrane, $25 \mathrm{~mm}$ pore size $0.45 \mu \mathrm{m}$ (MF-Milipore) previously dried in the microwave at $350 \mathrm{~W}$ for $20 \mathrm{~min}$. and weighed. To determine dry weight, the cells in the membrane were carefully washed with $1 \mathrm{ml}$ of water and dried under the same conditions. The values obtained are expressed as $\mu \mathrm{g}$ of glycerol per mg of yeast cells. Experiments were performed in triplicate.

\section{Gene Expression Determination}

For each culture, 10-20 ml sample was taken at different times. The cells were quickly harvested by centrifugation, washed and frozen in liquid $\mathrm{N}_{2}$. Then, frozen cells were lysed and homogenized by FastPrep-24 (MP Biomedicals) in LETS buffer (10 mm Tris $\mathrm{pH} 7.4,10 \mathrm{mM}$ lithium-EDTA, $100 \mathrm{mM}$ lithium chloride, $1 \%$ lithium lauryl sulfate) with acid-washed glass beads (0.4 mm diameter; Sigma-Aldrich) for $30 \mathrm{~s}$ six times alternating with ice incubation. Total RNA was extracted and purified using the phenol:chloroform method with minor modifications (Combina et al., 2012). Then the RNA was converted to cDNA and the expression of GPD1, GPD2, STL1, and FPS1 genes was quantified by qRT-PCR (quantitative real-time PCR). The cDNA strand was constructed using $2 \mu \mathrm{g}$ of RNA mixed with $0.8 \mathrm{mM}$ dNTP's, $80 \mathrm{pmol}$ Oligo (dT) in $13 \mu \mathrm{l}$. The mixture was heated to $65^{\circ} \mathrm{C}$ for $5 \mathrm{~min}$ and quenched on ice for $1 \mathrm{~min} .5 \mathrm{mM}$ dithiothreitol (DTT), $50 \mathrm{U}$ of RNase inhibitor (Invitrogen), $1 \times$ First Strand Buffer (Invitrogen) and $200 \mathrm{U}$ Superscript III (Invitrogen) were added to the $20 \mu \mathrm{l}$ mixture, which was incubated at $50^{\circ} \mathrm{C}$ for $60 \mathrm{~min}$ and the reaction was inactivated after $15 \mathrm{~min}$ at $70^{\circ} \mathrm{C}$. qRT-PCR was performed with gene-specific primers $(200 \mathrm{nM})$ designed for each specie (Table 2) from sequences consensus between the different strains in a $10 \mu \mathrm{l}$ reaction, using the Light Cycler FastStart DNA MasterPLUS SYBR green (Roche Applied Science, Germany) in a LightCycler ${ }^{\circledR} 2.0$ System (Roche Applied Science, Germany). All samples were processed for melting curve analysis, amplification efficiency and DNA concentration determination. A mixture of all samples and serial dilutions $\left(10^{-1}\right.$ to $\left.10^{-5}\right)$ was used as standard curve. Two different constitutive reference genes were used (ACT1 and RDN18-1) to normalize the amount of mRNA and ensure accuracy, correct interpretation, and repeatability (Starovoytova et al., 2013). The results were normalized by using the normalization factor obtained from geNorm VBA applet (Vandesompele et al., 2002). 
TABLE 2 | Primers used in this study.

\begin{tabular}{|c|c|c|c|}
\hline Name & Sequence & Purpose & Species \\
\hline GPD1-F & TGTGGTGCTITGAAGAACG & qPCR and sequencing & S.c., S.u., S.p., S.k. \\
\hline GPD1-R & GTTCTTCTCTAGATTCTGG & QPCR and sequencing & S.c., S.u., S.p., S.K. \\
\hline GPD2-R & СCATCCCATACCTTCTACG & qPCR & S.c., S.u., S.p., S.k. \\
\hline FPS1-F & GTITGYGTITTCCAAAGC & qPCR & S.c., S.u., S.p., S.K. \\
\hline STL1-R & TGTTAACAGCATCGTGAAGC & qPCR & S.c., S.u., S.p. \\
\hline STL1-F & ACAGCATCGTGAAGCATAGC & qPCR & S. kudriavzevii \\
\hline STL1-R & TGGCTGATITCTCAAAGTCG & qPCR & S. kudriavzevii \\
\hline ACT1-F & CATGTTCCCAGGTATTGCCG & qPCR & S.c., S.u., S.p., S.k. \\
\hline ACT1-R & GCCAAAGCGGTGATTTCCT & qPCR & S.c., S.u., S.p., S.K. \\
\hline ScSTL1 - R2 & CAACCCTGTTCCAACACC & Verification & S. cerevisiae \\
\hline ScSTL1 - F2 & GGACAGTCCGGTTGGGGTTG & Verification & S. cerevisiae \\
\hline SbSTL1 - F2 & СTACCCTGAAACTGCTGG & Verification & S. uvarum \\
\hline SbSTL1 - R2 & GCCCAGTAGTCACGGAAAGC & Verification & S. uvarum \\
\hline SkSTL1 - F2 & CCCTGAAACCGCTGGTAG & Verification & S. kudriavzevii \\
\hline SkSTL1 - R2 & GCCTTGGACATTTCGGAC & Verification & S. kudriavzevii \\
\hline YEp352-R & GGGGATGTGCTGCAAGGCG & Verification & \\
\hline YEp-SbSTL1-F & GTACATTATAAAAAAAAATCCTGAACTTAGCTAGATATTATGAAGGAATCAAAAGTATCTAAG & Cloning YEp352 & S. uvarum \\
\hline YEp-SbSTL1-R & CACGACGTTGTAAAACGACGGCCAGTGCCAAGCTTGCATGTTACTITCAGAGCTGTITCAT & Cloning YEp352 & S. uvarum \\
\hline YEp-ScSTL1-F & GTACATTATAAAAAAAAATCCTGAACTTAGCTAGATATTATGAAGGATTTAAAATTATCG & Cloning YEp352 & S. cerevisiae \\
\hline YEp-ScSTL1-R & CACGACGTTGTAAAACGACGGCCAGTGCCAAGCTTGCATGTCAACCCTCAAAATTGGTT & Cloning YEp352 & S. cerevisiae \\
\hline
\end{tabular}

\section{RESULTS}

\section{Saccharomyces Species Differ in Tolerance to hyperosmotic and Cold Stresses}

The behavior of S. cerevisiae and other Saccharomyces species interesting for industrial applications was evaluated in response to wine fermentation relevant stresses. We selected hyperosmotic $(\mathrm{NaCl} 0.8 \mathrm{M}$ and $\mathrm{KCl} 1.25 \mathrm{M}$ ) and a combination of hyperosmotic and cold stresses $\left(12^{\circ} \mathrm{C}\right)$, two frequent suboptimal conditions during winemaking. We performed a drop test with two strains of each species (S. paradoxus, S. cerevisiae, S. kudriavzevii, and S. uvarum) on complete media and compared the growth in the above mentioned conditions (Figure 1). The results revealed that the used stresses have a very different effect on yeast growth depending not only on the species but even on the strain. The stress with $\mathrm{KCl} 1.25 \mathrm{M}$ is the condition that has less effect on the yeast growth capacity, and the $\mathrm{NaCl} 0.8 \mathrm{M}$ plus $12^{\circ} \mathrm{C}$ the most severe stress. The conditions $\mathrm{NaCl} 0.8 \mathrm{M}$ hyperosmotic stress and $\mathrm{KCl} 1.25 \mathrm{M}$ at $12^{\circ} \mathrm{C}$ hyperosmotic-cold stress generated intermediate growth capacity levels. The results showed clearly that the strains can cope better with a higher osmotic stress $(\mathrm{KCl} 1.25 \mathrm{M})$ than with the sodium toxicity $(\mathrm{NaCl} 0.8 \mathrm{M})$. In hyperosmotic stress mediated by $\mathrm{NaCl} 0.8 \mathrm{M}$ we observed that
S. uvarum strains are the ones presenting the highest tolerance to hyperosmotic and a similar observation can be made in the most severe condition $\left(\mathrm{NaCl} 0.8 \mathrm{M}\right.$ plus $\left.12^{\circ} \mathrm{C}\right)$. The other species showed similar behavior although $S$. kudriavzevii strains showed low growth levels in cold stress condition, especially IFO1802 strain. S. cerevisiae and $S$ paradoxus strains showed similar growth levels but strain 108 in $\mathrm{NaCl} 0.8 \mathrm{M}$ at $25^{\circ} \mathrm{C}$ and strain Chr16.2 in $\mathrm{KCl} 1.25 \mathrm{M}$ at $12^{\circ} \mathrm{C}$ presented lower growth levels than $S$. cerevisiae strains.

\section{Glycerol Levels during Wine Fermentation}

Since hyperosmotic and also cold stress responses are unequivocally related to glycerol accumulation we wanted to determine glycerol levels during hyperosmotic-cold stress in wine fermentations. Thus we performed wine fermentations in synthetic must with the studied Saccharomyces species and strains, and we measured intra- and extracellular amount of glycerol during the first hours and days of the fermentation. In the results presented in Figure 2 we observed two steps regarding glycerol accumulation in S. cerevisiae strains. In the first step, glycerol starts to accumulate inside the cell (Figure 2B) immediately after inoculating into the cold-hyperosmotic condition, reaching a maximal value after $24 \mathrm{~h}$. Also, minimal 


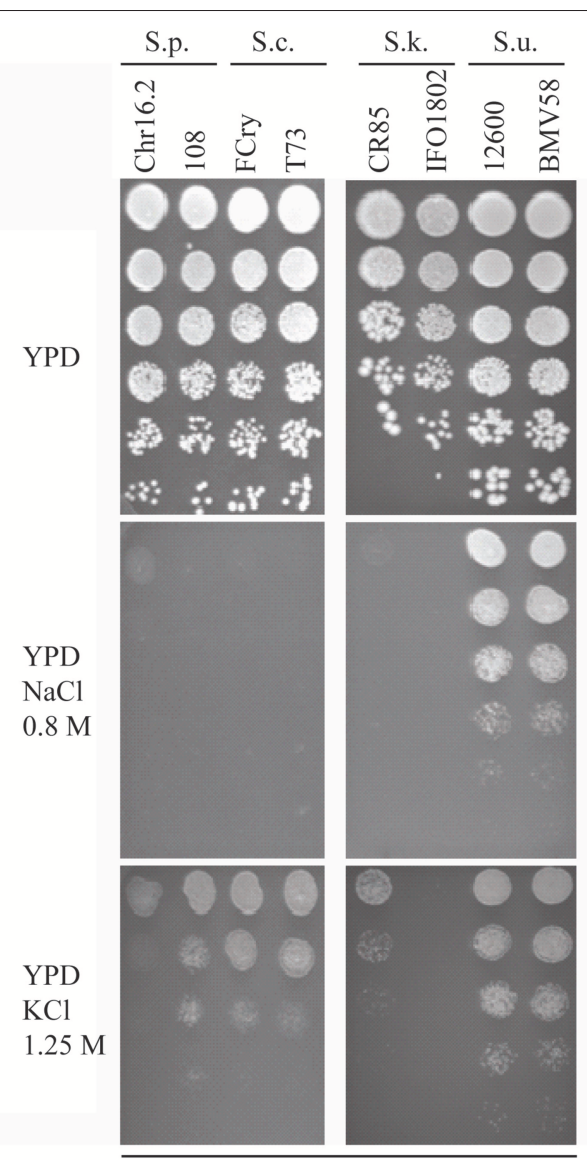

$12{ }^{\circ} \mathrm{C}$

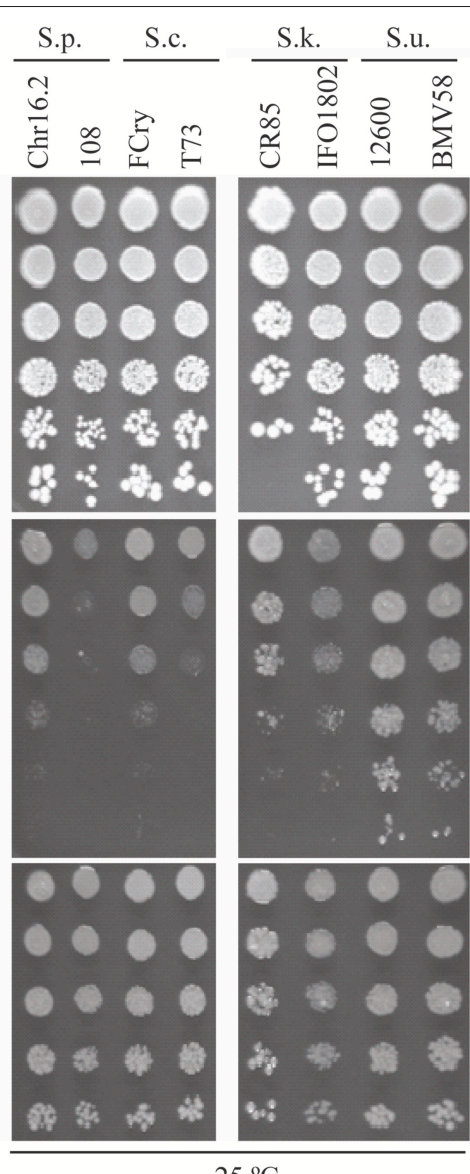

$25^{\circ} \mathrm{C}$

FIGURE 1 | Osmotolerance of S. paradoxus (S.p., Chr16.2, 108), S. cerevisiae (S.c. FCry, T73), S. kudriavzevii (S.k., CR85, IFO1802), and S. uvarum (S.u.12600, BMV58) strains at $\mathbf{2 5}$ and $\mathbf{1 2}^{\circ} \mathbf{C}$. Serial dilutions were plated in rich media with (YPD $\mathrm{NaCl} 0.8 \mathrm{M}$ or $\left.\mathrm{KCl} 1.25 \mathrm{M}\right)$ or without (YPD) hyperosmotic stress. A representative image of biological triplicates is presented.

glycerol levels are accumulated in extracellular media in the beginning of our experiment (Figure 2A). In the next 2 days, intracellular glycerol is reduced and tends to recover its original levels whereas extracellular glycerol increases with the time. In the case of S. paradoxus and S. kudriavzevii, maximal intracellular glycerol accumulation, which are approximately half of those in $S$. cerevisiae strains, occurs in the first hours and levels are maintained during $48 \mathrm{~h}$. Analyzing the intracellular glycerol level (Figure 2B), it is interesting to note that, comparing with the other species, $S$. cerevisiae strains accumulated the higher levels of glycerol between 4 and $48 \mathrm{~h}$ of incubation. The S. uvarum strains showed the lowest values of intracellular glycerol with a maximal level after $1 \mathrm{~h}$ in the case of BMV58 and after $48 \mathrm{~h}$ in the case of 12600 . Regarding extracellular glycerol (Figure 2A), S. paradoxus presented similar levels and accumulation pattern as $S$. cerevisiae and $S$. uvarum and, in addition, $S$. kudriavzevii showed a similar pattern but higher accumulation levels (around five times more). Is interesting to emphasize that S. uvarum and S. kudriavzevii showed a higher extracellular glycerol accumulation rate compared to the other two species. Interestingly, no extracellular glycerol was observed at time 0 in any species. It should be noted that strains do not show significant growth after 1 or $4 \mathrm{~h}$ and maximal yeast biomass was observed at the 24 or $48 \mathrm{~h}$ time point except for the IFO1802 that show very low growth level in grape must (Supplementary Figure 1), in concordance with data observed in Figure 1 in osmotic and cold stress conditions.

\section{Changes in mRNA Levels of Genes Related to Glycerol Balance during Wine Fermentation and Hyperosmotic stress of Different Saccharomyces Species}

To gain insights on the regulation of glycerol pools balance we studied variation in mRNA levels of key genes related to glycerol biosynthesis (GPD1 and GPD2), efflux (FPS1), and influx (STL1) in the same wine fermentation conditions described above and in the same strains and species. The results (Figure 3) clearly revealed different patterns and levels of gene expression among the species in all four genes studied. In the case of GPD1, all the strains showed a general pattern of induction after the first hour but with marked differences in the expression levels. $S$. 

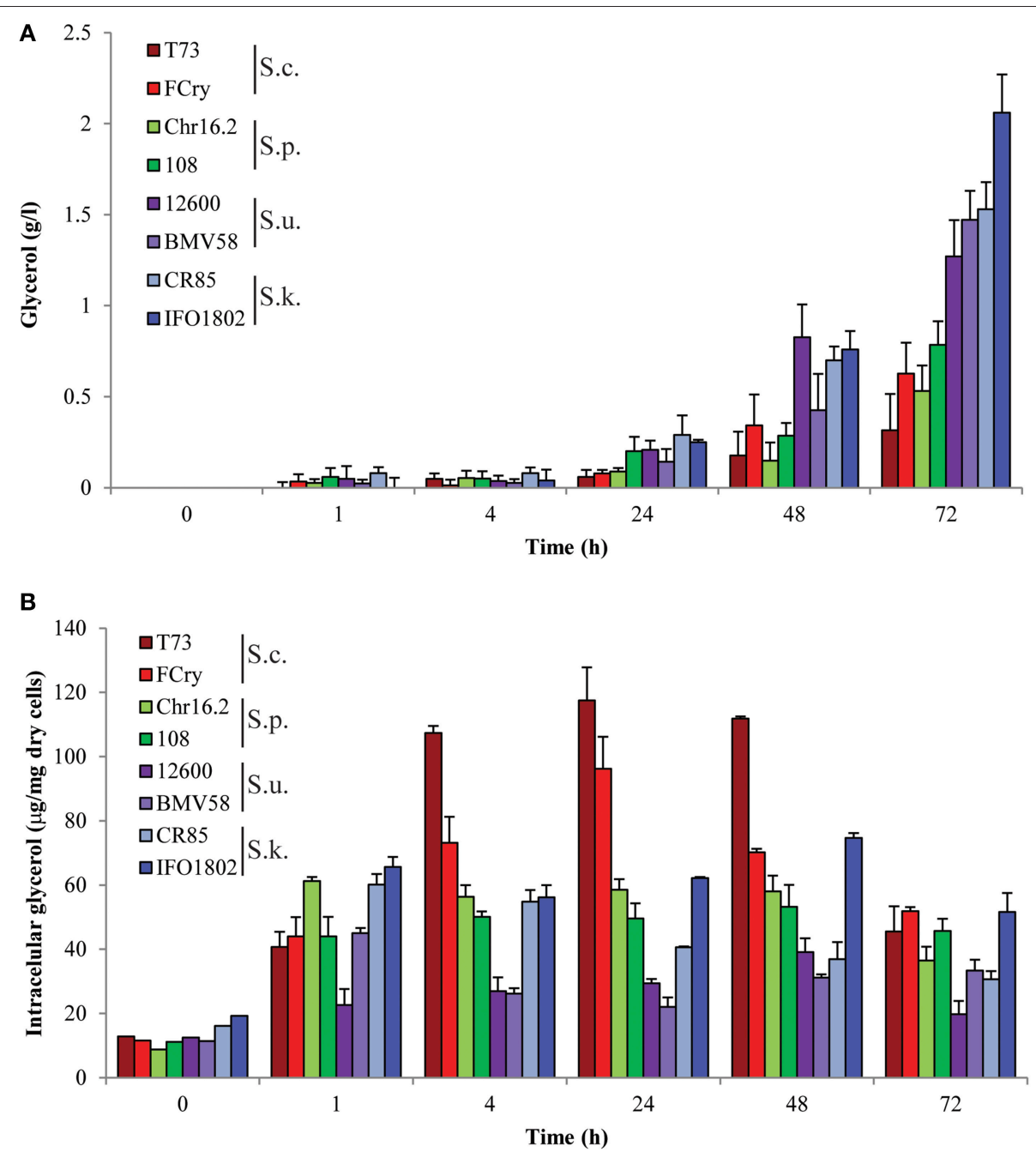

FIGURE 2 | Microvinification experiments in synthetic must at low temperature with S. cerevisiae T73 (dark red) and FCry (light red), S. paradoxus Chr16.2 (light green) and 108 (dark green), S. uvarum 12600 (dark purple) and BMV58 (light purple), and S. kudriavzevii CR85 (light blue) and IFO1802 (dark blue) strains. Precultured cells were inoculated in synthetic must at $12^{\circ} \mathrm{C}$ and samples were taken after $0,1,4,24$ and $48 \mathrm{~h}$ to determine extra (A) and intracellular (B) glycerol content for each strain. Three independent microvinification bottles were used for each strain and average \pm standard deviation is shown.

kudriavzevii strains showed the highest mRNA levels, specially IFO1802 strain that presented elevated expression of GPD1 before stress and even more after $1 \mathrm{~h}$ of inoculation. For the GPD2 gene, which is mainly involved in redox balance, some of the strains presented an induction with maximal levels after four (S. uvarum strains, FCry, 108, and CR85) or 48 (T73) hours whereas other strains (Chr16.2 and IFO1802) seem to not activate this gene showing low mRNA levels. The FPS1 gene expression peaked after $1 \mathrm{~h}(108, \mathrm{CR} 85$, S. cerevisiae, and S. uvarum strains) or $4 \mathrm{~h}$ (Fcry), with the $S$. cerevisiae and S. uvarum strains showing the highest levels. The IFO1802, Chr16.2, and S. kudriavzevii strains did not showed significant increase of mRNA levels compared to the inoculum. Finally, the SLT1 gene presented the most variable mRNA levels among the species showing highest values for the S. uvarum strains, especially BMV58, with a maximum after $1 \mathrm{~h}$. Other species showed a moderate amount of mRNA with maximum levels after $1 \mathrm{~h}$ (S. kudriavzevii strains) or $4 \mathrm{~h}$ (Fcry). S. paradoxus strains showed very low SLT1 mRNA levels along the experiment. Yeast growth phase does not has a dramatic impact in activation of gene expression in this conditions since the most important inductions were observed at 1 and $4 \mathrm{~h}$, were grow was not observed. The comparison between glycerol content and gene expression results emphasize the importance of GPD1 and STL1 in S. kudriavzevii and S. uvarum respectively, regarding their increased glycerol accumulation (Figure 2A). In the case of $S$. cerevisiae strains, increased GPD2 levels, especially in Fcry strain, could explain the high intracellular glycerol levels observed in Figure 2B. On the contrary, FPS1 increased expression does not reflect extracellular glycerol levels in S. cerevisiae probably due to the tight regulation of this channel by posttranslational mechanisms. 


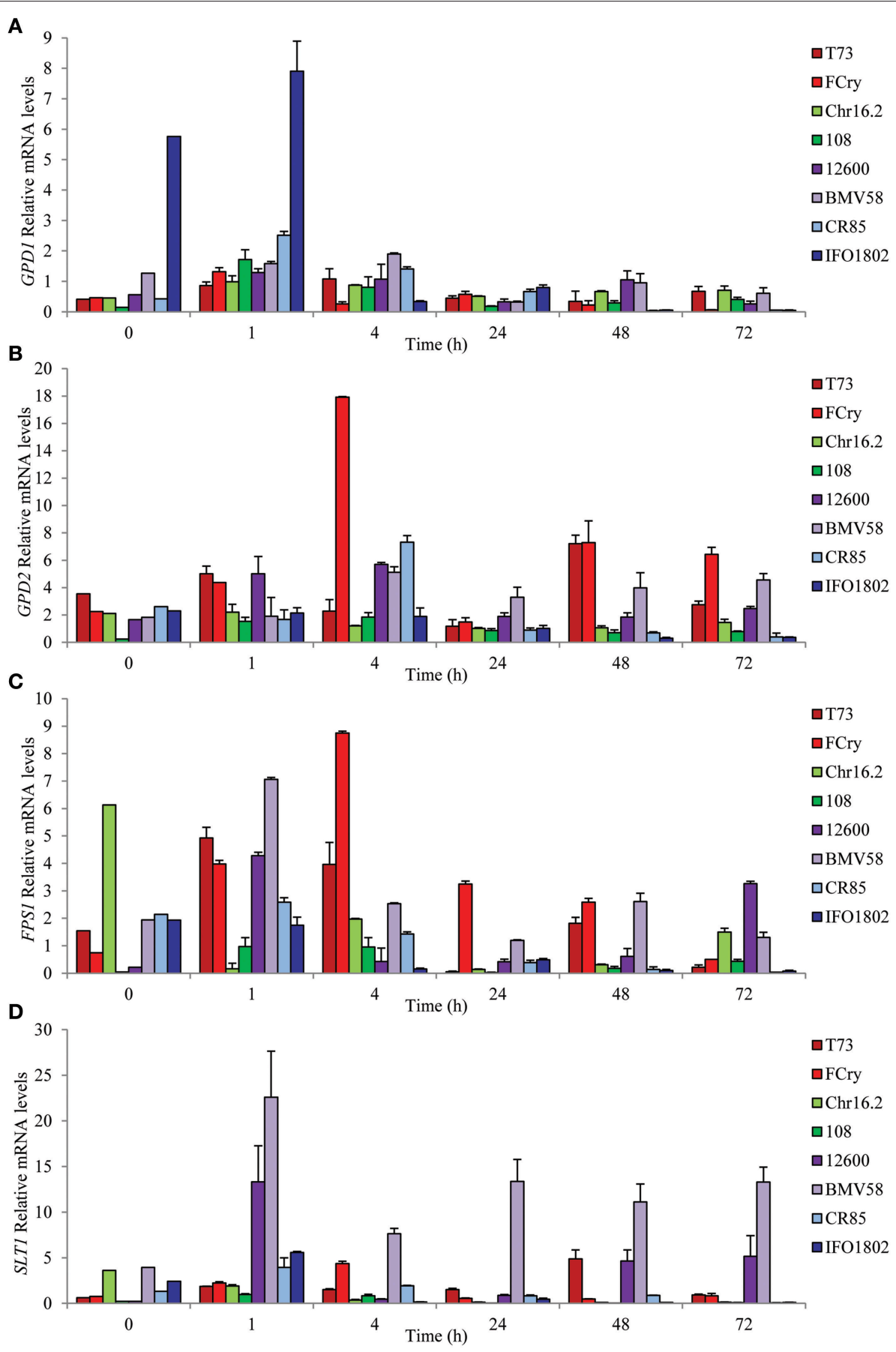

FIGURE 3 | Expression of glycerol balance related genes during first hours of low temperature microvinifications in synthetic must for S. cerevisiae T73 (dark red) and FCry (light red), S. paradoxus Chr16.2 (light green) and 108 (dark green), S. uvarum 12600 (dark purple) and BMV58 (light purple) and S. kudriavzevii CR85 (light blue) and IF01802 (dark blue) strains. The genes related to glycerol biosynthesis, GDP1 (A) and GPD2 (B), and glycerol export, FPS1 (C), and import, STL1 (D), were studied. Samples were taken in the first part (0, 1, 4, 24, 48 and $73 \mathrm{~h})$ of synthetic must microvinifications at $12^{\circ} \mathrm{C}$. After RNA extraction, expression of the different genes was determined by GPCR and values were normalized with ACT1 and RDN18-1 constitutive genes. Three independent microvinification bottles were used for each strain and averages \pm standard deviation are shown.

To study the regulation of key genes related to intracellular glycerol balance under standard lab conditions (Figure 4) we used a representative strains of each species (T73, Chr16.2,
BMV58, and IFO1802) and measured mRNA levels of GPD1, STL1 and FPS1 after half, 1 and $2 \mathrm{~h}$ of transfer cells to a nonstress SC media (Figure 4A), hyperosmotic SC $1 \mathrm{M}$ sorbitol 
A
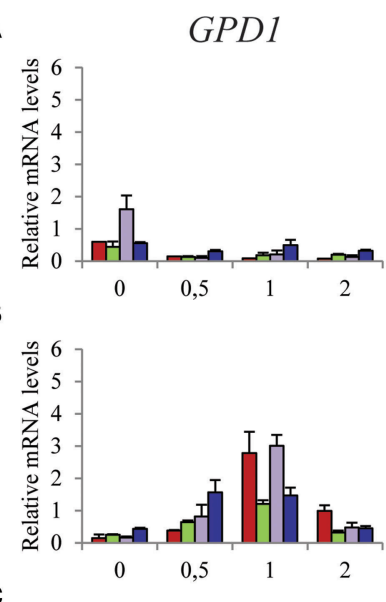

C
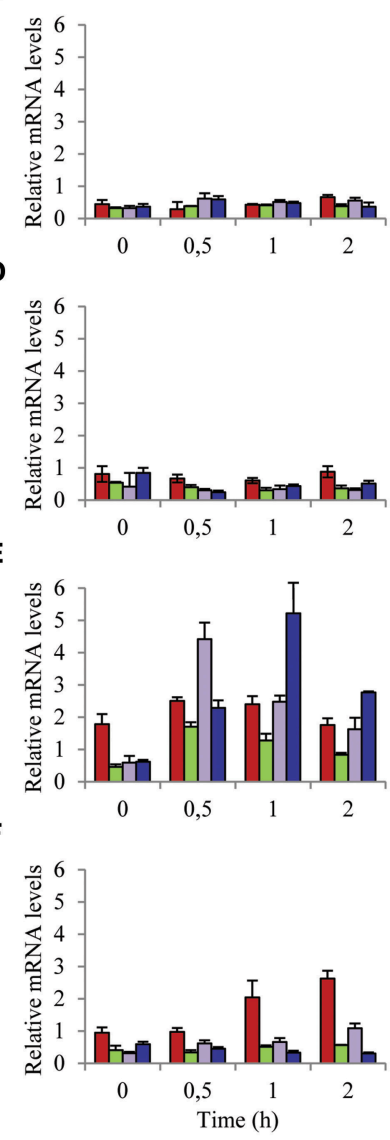

STL1
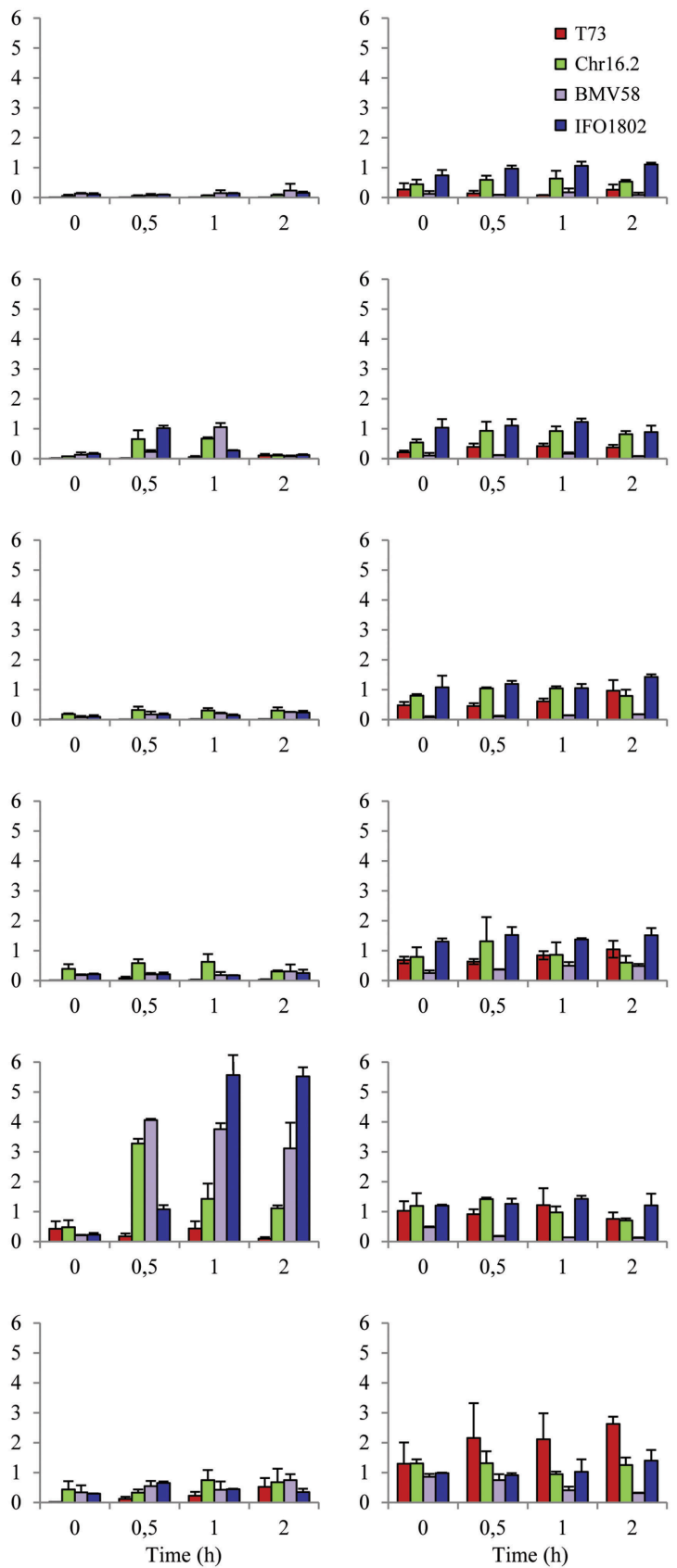

FPSI

$\mathrm{T} 73$

Chr16.2

口 BMV58

- IFO1802
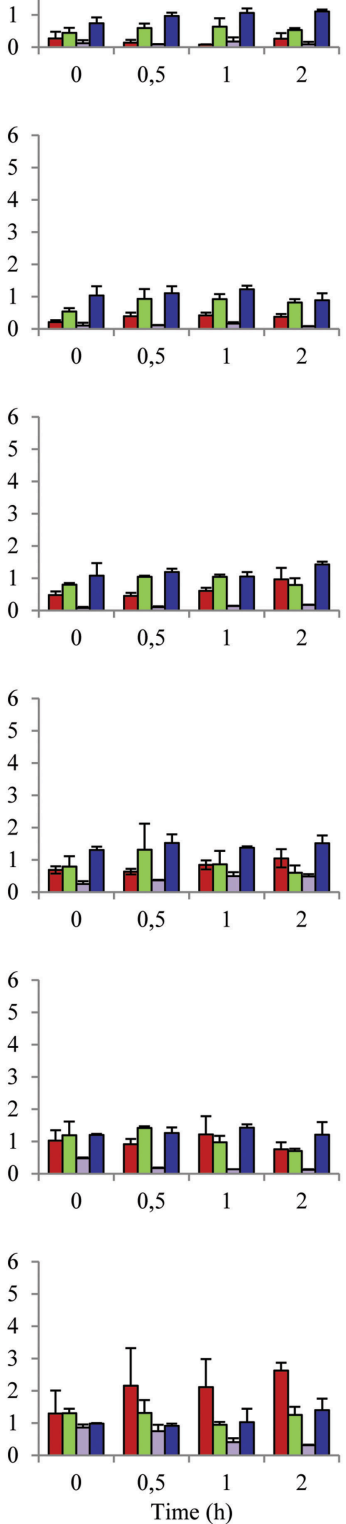

FIGURE 4 | Expression of glycerol balance related genes of S. cerevisiae T73 (red), S. paradoxus Chr16.2 (green), S. uvarum BMV58 (purple), and S. kudriavzevii IF01802 (blue) strains in various conditions. The genes related to glycerol biosynthesis (GDP1) and glycerol transport (FPS1 and STL1) were studied. Samples from non-stress SC media (A,D), hyperosmotic SC $1 \mathrm{M}$ sorbitol (B,E) or hypoosmotic (water) media (C,F) cultures were taken after 0, 0.5, 1 and $2 \mathrm{~h}$ of the inoculation (from pre grown cultures in SC). The SC media were supplemented with $2 \%$ glucose (A-C) or $2 \%$ mannitol (D-F) as a carbon source. After RNA extraction, expression of the different genes was determined by qPCR and values were normalized with ACT1 and RDN18-1 constitutive genes. Three independent microvinification bottles were used for each strain and averages \pm standard deviation are shown.

(Figure 4B) or hypoosmotic (water) media (Figure 4C). In addition, another analog set of experiments were performed but using mannitol as a carbon source (Figures $4 \mathrm{D}-\mathrm{F}$ ), which is a non-fermentable carbon source that complicates the energy supply for cellular processes. No yeast growth was observed during this experiment (results not shown). We can observe that all strains, especially T73 and BMV58, activate GPD1 0.5-1 h after hyperosmotic stress (Figure 4B) but is not activated in non-stress 


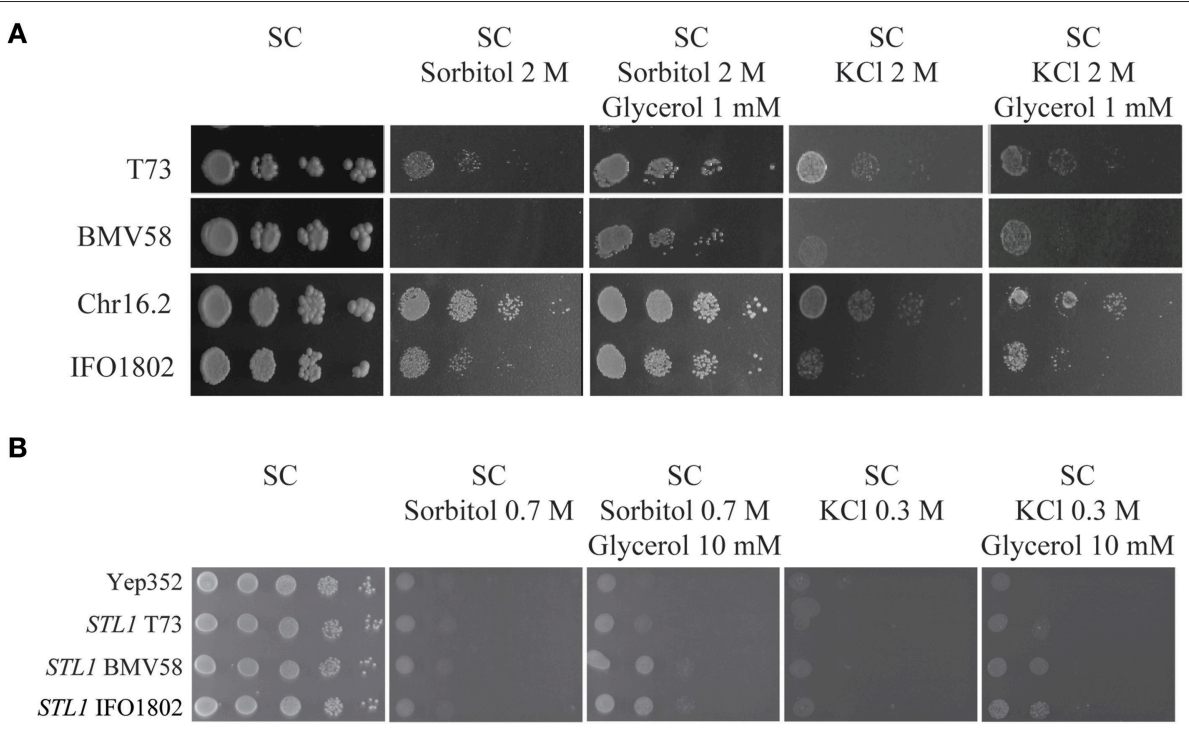

C

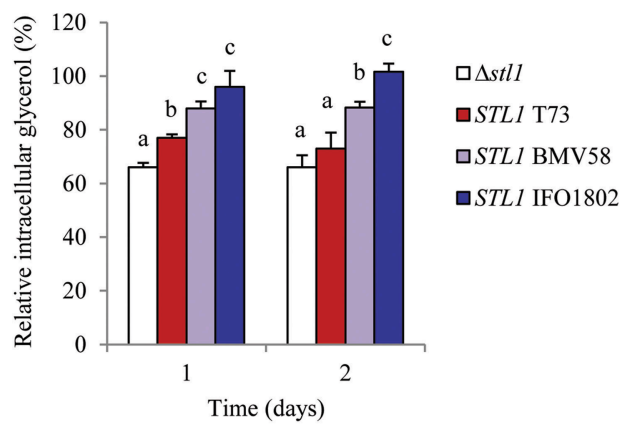

FIGURE 5 | Importance of glycerol import for osmotolerance of S. cerevisiae (T73), S. uvarum (BMV58) S. paradoxus (Chr16.2), and S. kudriavzevii (IFO1802) in drop test assays. (A) Serial dilutions of the different strains were plated in non-stress media (SC), in hyperosmotic stress media (SC with $2 \mathrm{M}$ sorbitol or $2 \mathrm{M} \mathrm{KCl}$ ) and in hyperosmotic stress media supplemented with glycerol (1 mM glycerol) (B) Growth of S. cerevisiae BY4741 $\Delta$ st/1 $\Delta$ hog 1 strain expressing STL1 alleles from S. cerevisiae (T73), S. uvarum (BMV58) or S. kudriavzevii (IFO1802) was monitored in drop tests on non-stress media (SC), in hyperosmotic stress media (SC with $0.7 \mathrm{M}$ sorbitol or $0.3 \mathrm{M} \mathrm{KCl}$ ), and in hyperosmotic stress media supplemented with $10 \mathrm{mM}$ glycerol. A representative image of biological triplicates is presented. (C) In the same strains used in (B), intracellular glycerol accumulation was measured collecting samples after 0, 1, or 2 days of growth in SC with 10\% glucose. Cells precultured in the same media were inoculated $\left(\mathrm{OD}_{600}=0.3\right)$ and incubated at $25^{\circ} \mathrm{C}$ in $100 \mathrm{ml}$ flasks. Data in time 0 for each strain was considered $100 \%$. Three independent experiments were performed for each strain and averages \pm standard deviation are shown. ANOVA with fisher test ( $p<0.05)$ was performed and significantly different values are labeled with different letters.

conditions (Figure 4A) or hypoosmotic stress (Figure 4C). A similar situation but with higher mRNA levels is observed in presence of mannitol instead of glucose where hyperosmotic stress (Figure 4E) activates GPD1 gene, especially for BMV58 and IFO1802. In this case, hypoosmotic stress (Figure 4F) does activate the GPD1 gene in the case of T73 and BMV58. The STL1 gene reacts with a similar patter as GPD1 increasing mRNA levels in hyperosmotic stress (Figure 4B) but not upon hypoosmotic stress in the presence of glucose (Figure 4C). STL1 shows also a similar patter as GPD1 in presence of mannitol, increasing expression levels after hyperosmotic stress (Figure 4E), though to higher levels compared to glucose (Figures 4B,E). Interestingly, S. cerevisiae T73 strain shows very low STL1 levels in any conditions and no significant activation (Figure 4F). On the contrary, the FPS1 gene seems to be unresponsive to any condition in all the strains with except for the case of T73 growth in mannitol and hypoosmotic stress (Figure 4F). Similar levels are presented for all strains and conditions although BMV58 presented lower levels that the other strains. Altogether, it is the STL1 gene whose expression shows the highest level of variation in different conditions and among the species and strains.

\section{Stl1 Functional differences in Saccharomyces Species}

Since STL1 gene presented important differences in mRNA levels in strains from different Saccharomyces species we wanted to study the possible functional differences of this glycerol importer. For that we first compared the growth of a representative strain of 
S. cerevisiae (T73), S. uvarum (BMV58), S. paradoxus (Chr16.2), and S. kudriavzevii (IFO1802) species in conditions where the activity of Stll is important (Figure 5A). A drop test with the four strains was performed in non-stress media (SC), in hyperosmotic stress media (SC with $2 \mathrm{M}$ sorbitol or $2 \mathrm{M} \mathrm{KCl}$ ) and in hyperosmotic stress media supplemented with a very low amount of glycerol (SC with $2 \mathrm{M}$ sorbitol (or $2 \mathrm{M} \mathrm{KCl}$ ) and $1 \mathrm{mM}$ glycerol). In these conditions, if the cells are able to efficiently import glycerol to the cytosol they have a growth advantage when extracellular glycerol is present, i.e., before they synthesize the necessary amount to counterbalance the external osmotic pressure. The results show that cell growth is affected by hyperosmotic stress conditions proportionally to the osmotic pressure, i.e., more in the presence of $2 \mathrm{M} \mathrm{KCl}$ than in the presence of $2 \mathrm{M}$ sorbitol. We can observe that BMV58 is the strain with the lowest and Chr16.2 the highest survival level in both hyperosmotic stress conditions. Interestingly, as shown in the Figure 5A, some strains, as IFO1802 and especially BMV58, benefit from the presence of glycerol in the medium more than others (e.g., T73 and Chr16.2). These results are indicative of different capacity to import glycerol in response to hyperosmotic stress among the studied strains. Is interesting to highlight that osmotolerances in minimal media can be different to complete media (see BMV58 in Figure 1 compared to Figure 5A). This reflects that strains disposition to cope to osmotic stress could be different since complete and minimal media induce very different gene expression programs (Gasch et al., 2000; Miura et al., 2008).

To confirm these Stl1 functional differences we cloned the different STL1 alleles from T73, BMV58, and IFO1802 strains in an $S$. cerevisiae multicopy plasmid behind a weak and constitutive promoter, and expressed them in a laboratory osmosensitive S. cerevisiae strain (BY4741 $\Delta$ slt1 $\Delta$ hog1). As a control, this strain was also transformed with the empty YEp352. Then, the growth of strains was tested in non-stress media (SC), in hyperosmotic-stress media (SC with $0.7 \mathrm{M}$ sorbitol or $0.3 \mathrm{M}$ $\mathrm{KCl})$ and in hyperosmotic-stress media supplemented with extracellular glycerol (SC $0.7 \mathrm{M}$ sorbitol or $0.3 \mathrm{M} \mathrm{KCl}$, and $10 \mathrm{mM}$ glycerol). The results (Figure 5B) showed that the strains with the BMV58 and IFO1802 SLT1 allele are clearly able to recover growth when they have extracellular glycerol in the presence of a hyperosmotic stress. However, the strain containing the T73 STL1 allele presented only a minor growth recovery when it can use extracellular glycerol in the presence of a hyperosmotic stress.

We also evaluated the different Slt1 functionality by measuring the intracellular glycerol accumulation of the $S$. cerevisiae strains expressing different STL1 genes after 1 and 2 days of growth in 10\% glucose (Figure 5C) without any additional osmotic agents. The strain with IFO1802 Stl1 was able to recover the original intracellular glycerol levels by importing some of the diffused out glycerol. The strain with BMV58 Stll was able to recover more than $80 \%$ of the original intracellular glycerol levels. On the contrary, after 2 days the strain with the T73 Stll showed intracellular glycerol levels recovery no significantly different than a strain without Slt1. This results points in the same direction of the previous experiments and suggest a low functionality of T73 Stl1 compared with BMV58 and IFO1802.

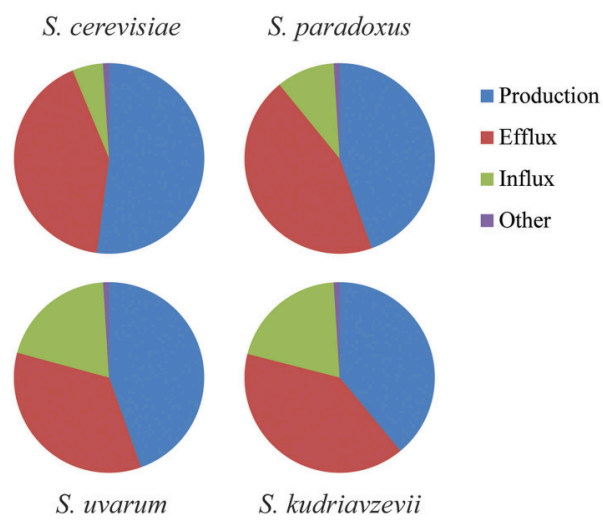

FIGURE 6 | Schematic representation of the weight of glycerol production, efflux, influx, or other actions regarding glycerol balance after hyperosmotic stress. This representation compares the dynamics of glycerol accumulation in response to hyperosmotic stress that has been quantitatively analyzed and modeled using physiologic, metabolic, enzymatic, and transcriptomic data of the key actors in S. cerevisiae (Petelenz-Kurdziel et al., 2013). Here we compared with the other species (S. paradoxus, S. uvarum, and S. kudriavzevii) using data provided in this work and others as Oliveira et al. (2014).

\section{DISCUSSION}

In this work we studied intracellular glycerol pool balance and regulation in response to stresses that occur upon inoculating wine-related yeast species in grape musts. We have analyzed strains belonging to four species that participate in winemaking directly (S. cerevisiae, S. uvarum, and S. paradoxus) or through hybrids (S. kudriavzevii). A first approach was to compare survival of these species during hyperosmotic and coldhyperosmotic stress. Other studies have found that $S$. cerevisiae, $S$. uvarum, and $S$. paradoxus strains have similar tolerance to hyperosmotic stress whereas $S$. kudriavzevii strains show a decreased survival in $15 \%$ sorbitol at $30^{\circ} \mathrm{C}$ (Wimalasena et al., 2014). However, this result is doubtful since S. kudriavzevii strains are sensitive to this temperature (Arroyo-López et al., 2010). In our results using $25^{\circ} \mathrm{C}$, an optimal temperature for S. kudriavzevii, this species shows similar or slightly higher tolerance to some hyperosmotic conditions compared to $S$. cerevisiae and S. paradoxus. In contrast, we observed an increased hyperosmotic stress tolerance in S. uvarum strains that is even more evident in hyperosmotic-cold stress conditions, where glycerol balance is determinant for cell survival. These results argue in favor to a more efficient handling of intracellular glycerol in S. uvarum strains in this condition. On the contrary, hyperosmotic tolerances in Saccharomyces species seems to be dependent on the media since $S$. uvarum strain BMV58 shows the lowest hyperosmotic tolerance in minimal media (Figure 5A) instead of the highest tolerance in complete media (Figure 1). All these data point to different strategies in the different species to handle glycerol accumulation in response to hyperosmotic or cold-hyperosmotic stresses.

In winemaking conditions, cells suffer hyperosmotic or cold hyperosmotic mild stresses that do not affect cell growth 
capacity in any Saccharomyces species (results not shown). This hyperosmotic stress produced by the elevated amount of sugars may determine different lag phase adaptations. In fact, significant differences can be observed in extra and intracellular glycerol levels and also in gene expression of key genes involved in glycerol homeostasis. These data also suggest that the Saccharomyces species are using different strategies to face alterations in the osmotic pressure and cold temperatures. In fact this argument is not that surprising since Saccharomyces species are genetically quite distant showing coding region identities such as the one showed when comparing human and mouse (85\%; Lapidot et al., 2001). The dynamics of glycerol accumulation in hyperosmotic stress has been quantitatively analyzed and modeled using physiologic, metabolic, enzymatic, and transcriptomic data in S. cerevisiae (Petelenz-Kurdziel et al., 2013). The strategy of this species consists in a transcriptional activation of GPD1 to increase glycerol accumulation inside the cell by redirecting glycolytic flux. On the other hand, the glycerol efflux stops by the closing of Fps1channel. These are the principal mechanisms to balance glycerol after a hyperosmotic shock. Glycerol influx and other elements contribute in a minor fraction (Figure 6). From the results of this work and others, we can hypothesize that non-cerevisiae Saccharomyces species have changed the weight of the different elements involved in glycerol balance. Based on STL1 gene activation and Stl1 functionality assays we speculate that $S$. uvarum and $S$. kudriavzevii rely more in the glycerol import to compensate the osmotic pressure when extracellular glycerol is accumulated (Figure 6). This strategy is not exclusive of these species, In fact, it has been shown that the most osmotolerant yeasts species present a very efficient glycerol-import capacity (Lages et al., 1999).

A possible explanation of the different strategies applied by the Saccharomyces species to balance glycerol in osmotically non-optimal environments could be amount of intracellular glycerol that cells need to accumulate. We observed that, in our winemaking conditions, $S$. cerevisiae accumulates the highest amount of glycerol in the cells. This promotes the supposition that the other species can partially compensate the osmotic pressure by other means as cell volume changes for example. This will allow them to diversify the mechanisms available to compensate water efflux by using more frequently other elements that can be inefficient in specific situations, for example the glycerol import, which can be useless if there is no glycerol outside the cell. This variation could be

\section{REFERENCES}

Arroyo-López, F. N., Pérez-Torrado, R., Querol, A., and Barrio, E. (2010). Modulation of the glycerol and ethanol syntheses in the yeast Saccharomyces kudriavzevii differs from that exhibited by Saccharomyces cerevisiae and their hybrid. Food Microbiol. 27, 628-637. doi: 10.1016/j.fm.2010. 02.001

Bely, M., Rinaldi, A., and Dubourdieu, D. (2003). Influence of assimilable nitrogen on volatile acidity production by Saccharomyces cerevisiae during high sugar fermentation. J. Biosci. Bioeng. 96, 507-512. doi: 10.1016/S13891723(04)70141-3 consequence of environmental adaptation to different niches. For example, cold stress adaptations could implement glycerol influx to better cope with low temperatures. Future research will shed more light in the effect of other conditions as redox unbalance and anaerobiosis in the glycerol pools in the different species.

In summary, the four species studied show different strategies to survive under osmotic or cold-osmotic stressful conditions (Figure 6). In all species, the balance of intracellular glycerol which depends on the production, efflux, influx and other minor elements is altered in order to increase its levels. However, whereas a species as $S$. cerevisiae relays more in changes in the production levels, others tend to depend more on the variation of the influx as $S$. uvarum or S. kudriavzevii.

\section{AUTHOR CONTRIBUTIONS}

RP conceived the study and participated in its design and coordination and draft the manuscript. GMO and JZ performed the experiments and analyzed the results. HS and AQ participated in the design and coordination of the study and in the draft of the manuscript. All authors read and approved the final manuscript.

\section{ACKNOWLEDGMENTS}

BO was supported by CAPES the Brazilian Federal Agency for the Support and Evaluation of Graduate Education (Brazilian Ministry of Education). This work has been supported by grants AGL2012-39937-C02-01 and AGL2015-67504-C3-1-R from the Spanish Government, FEDER, and Generalitat Valenciana PROMETEOII/2014/042 to AQ, GA CR 15-03708S from the Czech National Foundation to HS, and by the European Commission FP7: Marie Curie Initial Training Network CORNUCOPIA no. 264717 to AQ and HS.

\section{SUPPLEMENTARY MATERIAL}

The Supplementary Material for this article can be found online at: http://journal.frontiersin.org/article/10.3389/fmicb. 2016.00435

Supplementary Figure 1 | Yeast biomass accumulation during low temperature microvinifications in synthetic must for S. cerevisiae T73 (dark red) and FCry (light red), S. paradoxus Chr16.2 (light green) and 108 (dark green), S. uvarum 12600 (dark purple) and BMV58 (light purple), and S. kudriavzevii CR85 (light blue) and IFO1802 (dark blue) strains. Chan, E. T. et al. (2012). Saccharomyces Genome Database: the genomics resource of budding yeast. Nucleic Acids Res. 40, 700-705. doi: 10.1093/nar/ gkr1029

Combina, M., Pérez-Torrado, R., Tronchoni, J., Belloch, C., and Querol, A. (2012). Genome-wide gene expression of a natural hybrid between Saccharomyces cerevisiae and S. kudriavzevii under enological conditions. Int. J. Food. Microbiol. 157, 340-345. doi: 10.1016/j.ijfoodmicro.2012. 06.001

de Nadal, E., Ammerer, G., and Posas, F. (2011). Controlling gene expression in response to stress. Nat. Rev. Genet. 12, 833-845. doi: 10.1038/nrg3055 
Demuyter, C., Lollier, M., Legras, J.-L., and Le Jeune, C. (2004). Predominance of Saccharomyces uvarum during spontaneous alcoholic fermentation, for three consecutive years, in an Alsatian winery. J. Appl. Microbiol. 97, 1140-1148. doi: 10.1111/j.1365-2672.2004.02394.x

Duskova, M., Borovikova, D., Herynkova, P., Rapoport, A., and Sychrova, H. (2015b). The role of glycerol transporters in yeast cells in various physiological and stress conditions. FEMS Microbiol. Lett. 362, 1-8. doi: 10.1093/femsle/fnu041

Dušková, M., Ferreira, C., Lucas, C., and Sychrová, H. (2015a). Two glycerol uptake systems contribute to the high osmotolerance of Zygosaccharomyces rouxii. Mol. Microbiol. 97, 541-559. doi: 10.1111/mmi. 13048

Gamero, A., Tronchoni, J., Querol, A., and Belloch, C. (2013). Production of aroma compounds by cryotolerant Saccharomyces species and hybrids at low and moderate fermentation temperatures. J. Appl. Microbiol. 114, 1405-1414. doi: 10.1111/jam. 12126

Gasch, A. P., Spellman, P. T., Kao, C. M., Carmel-Harel, O., Eisen, M. B., Storz, G. et al. (2000). Genomic expression programs in the response of yeast cells to environmental changes. Mol. Biol. Cell 11, 4241-4257. doi: $10.1091 / \mathrm{mbc} .11 .12 .4241$

Gonzalez, S. S., Gallo, L., Climent, M. A., Barrio, E., and Querol, A. (2007). Enological characterization of natural hybrids from Saccharomyces cerevisiae and S. kudriavzevii. Int. J. Food Microbiol. 116, 11-18. doi: 10.1016/j.ijfoodmicro.2006.10.047

Hohmann, S., Krantz, M., and Nordlander, B. (2007). Yeast osmoregulation. Methods Enzymol. 428, 29-45. doi: 10.1016/S0076-6879(07)28002-4

Hubmann, G., Guillouet, S., and Nevoigt, E. (2011). Gpd1 and Gpd2 finetuning for sustainable reduction of glycerol formation in Saccharomyces cerevisiae. Appl. Environ. Microbiol. 77, 5857-5867. doi: 10.1128/AEM. 05338-11

Kinclová, O., Ramos, J., Potier, S., and Sychrová, H. (2001). Functional study of the Saccharomyces cerevisiae Nhalp C-terminus. Mol. Microbiol. 40, 656-668. doi: 10.1046/j.1365-2958.2001.02412.x

Lages, F., Silva-Graça, M., and Lucas, C. (1999). Active glycerol uptake is a mechanism underlying halotolerance in yeasts: a study of 42 species. Microbiol. 145, 2577-2585. doi: 10.1099/00221287-145-9-2577

Landry, C. R., Townsend, J. P., Hartl, D. L., and Cavalieri, D. (2006). Ecological and evolutionary genomics of Saccharomyces cerevisiae. Mol. Ecol. 15, 575-591. doi: 10.1111/j.1365-294X.2006.02778.x

Lapidot, M., Pilpel, Y., Gilad, Y., Falcovitz, A., Sharon, D., Haaf, T. et al. (2001). Mouse-human orthology relationships in an olfactory receptor gene cluster. Genomics 71, 296-306 doi: 10.1006/geno.2000.6431

Le Jeune, C., Lollier, M., Demuyter, C., Erny, C., and Legras, J. L., al. (2007). Characterization of natural hybrids of Saccharomyces cerevisiae and Saccharomyces bayanus var. uvarum. FEMS Yeast Res. 7, 540-549. doi: 10.1111/j.1567-1364.2007.00207.x

Lopes, C. A., Barrio, E., and Querol, A. (2010). Natural hybrids of $S$. cerevisiae $x$ S. kudriavzevii share alleles with European wild populations of Saccharomyces kudriavzevii. FEMS Yeast Res. 10, 412-421. doi: 10.1111/j.15671364.2010.00614.x

López-Malo, M., Querol, A., and Guillamon, J. M. (2013). Metabolomic comparison of Saccharomyces cerevisiae and the cryotolerant species $S$. bayanus var. uvarum and $S$. kudriavzevii during wine fermentation at low temperature. PLOS ONE 8:e60135. doi: 10.1371/journal.pone.00 60135

Luyten, K., Albertyn, J., Skibbe, W. F., Prior, B. A., Ramos, J., Thevelein, J. M. et al. (1995). Fps1, a yeast member of the MIP family of channel proteins, is a facilitator for glycerol uptake and efflux and is inactive under osmotic stress. EMBO J. 14, 1360-1371.

Miura, F., Kawaguchi, N., Yoshida, M., Uematsu, C., Kito, K., Sakaki, Y. et al. (2008). Absolute quantification of the budding yeast transcriptome by means of competitive PCR between genomic and complementary DNAs. BMC Genomics 9:574. doi: 10.1186/1471-2164-9-574

Naumov, G. I., Naumova, E. S., Antunovics, A., and Sipiczki, M. (2002). Saccharomyces bayanus var. uvarum in Tokaj wine-making of Slovakia and Hungary. Appl. Microbiol. Biotechnol. 59, 727-730. doi: 10.1007/s00253-0021077-6
Oliveira, B. M., Barrio, E., Querol, A., and Pérez-Torrado, R. (2014). Enhanced enzymatic activity of glycerol-3-phosphate dehydrogenase from the cryophilic Saccharomyces kudriavzevii. PLoS ONE 9:e87290. doi: 10.1371/journal.pone.0087290

Panadero, J., Pallotti, C., Rodriguez-Vargas, S., Randez-Gil, F., and Prieto, J. A. (2006). A downshift in temperature activates the high osmolarity glycerol HOG pathway, which determines freeze tolerance in Saccharomyces cerevisiae. J. Biol. Chem. 281, 4638-4645. doi: 10.1074/jbc. M512736200

Pérez-Torrado, R., Gómez-Pastor, R., Larsson, C., and Matallana, E. (2009). Fermentative capacity of dry active wine yeast requires a specific oxidative stress response during industrial biomass growth. Appl. Microbiol. Biotechnol. 81, 951-960. doi: 10.1007/s00253-0081722-9

Pérez-Torrado, R., González, S. S., Combina, M., Barrio, E., and Querol, A. (2015). Molecular and enological characterization of a natural Saccharomyces uvarum and Saccharomyces cerevisiae hybrid. Int. J. Food Microbiol. 204, 101-110. doi: 10.1016/j.ijfoodmicro.2015.03.012

Peris, D., Sylvester, K., Libkind, D., Gonçalves, P., Sampaio, J. P., Alexander, W. G. et al. (2014). Population structure and reticulate evolution of Saccharomyces eubayanus and its lager-brewing hybrids. Mol. Ecol. 23, 2031-2045. doi: $10.1111 /$ mec. 12702

Petelenz-Kurdziel, E., Kuehn, C., Nordlander, B., Klein, D., Hong, K. K., Jacobson, T. et al. (2013). Quantitative analysis of glycerol accumulation, glycolysis and growth under hyper osmotic stress. PLoS Comput. Biol. 9:e1003084. doi: 10.1371/journal.pcbi.1003084

Pretorius, I. S., Curtin, C. D., and Chambers, P. J. (2012). The winemaker's bug: from ancient wisdom to opening new vistas with frontier yeast science. Bioeng. Bugs. 3, 147-156. doi: 10.4161/bbug.19687

Querol, A., Barrio, E., and Ramón, D. (1994). Population dynamics of natural Saccharomyces strains during wine fermentation. Int. J. Food Microbiol. 21, 315-323. doi: 10.1016/0168-1605(94)90061-2

Redžepović, S., Orlić, S., Sikora, S., Majdak, A., and Pretorius, I. S. (2002). Identification and characterization of Saccharomyces cerevisiae and Saccharomyces paradoxus strains isolated from Croatian vineyards. Lett. Appl. Microbiol. 35, 305-310. doi: 10.1046/j.1472-765X.2002.01181.x

Rementeria, A., Rodriguez, J. A., Cadaval, A., Amenabar, R., Muguruza, J. R., Hernando, F. L. et al. (2003). Yeast associated with spontaneous fermentations of white wines from 'Txakoli de Bizkaia' region Basque Country, North Spain. Int. J. Food Microbiol. 86, 201-207. doi: 10.1016/S0168-1605(03) 00289-7

Remize, F., Barnavon, L., and Dequin, S. (2001). Glycerol export and glycerol-3phosphate dehydrogenase, but not glycerol phosphatase, are rate limiting for glycerol production in Saccharomyces cerevisiae. Metab. Eng. 3, 301-312. doi: 10.1006/mben.2001.0197

Starovoytova, A. N., Sorokin, M. I., Sokolov, S. S., Severin, F. F., and Knorre, D. A. (2013). Mitochondrial signaling in Saccharomyces cerevisiae pseudohyphae formation induced by butanol. FEMS Yeast Res. 13, 367-374. doi: 10.1111/1567-1364.12039

Tronchoni, J., Gamero, A., Arroyo-López, F. N., Barrio, E., and Querol, A. (2009). Differences in the glucose and fructose consumption profiles in diverse Saccharomyces wine species and their hybrids during grape juice fermentation. Int. J. Food Microbiol. 134, 237-243. doi: 10.1016/j.ijfoodmicro.2009.07.004

Tronchoni, J., Medina, V., Guillamón, J. M., Querol, A., and Pérez-Torrado, R. (2014). Transcriptomics of cryophilic Saccharomyces kudriavzevii reveals the key role of gene translation efficiency in cold stress adaptations. BMC Genomics 15:432. doi: 10.1186/1471-2164-15-432

Tronchoni, J., Rozès, N., Querol, A., and Guillamón, J. M. (2012). Lipid composition of wine strains of Saccharomyces kudriavzevii and Saccharomyces cerevisiae grown at low temperature. Int. J. Food Microbiol. 155, 191-198. doi: 10.1016/j.ijfoodmicro.2012.02.004

Tulha, J., Lima, A., Lucas, C., and Ferreira, C. (2010). Saccharomyces cerevisiae glycerol/H+ symporter Stllp is essential for cold/near-freeze and freeze stress adaptation. A simple recipe with high biotechnological potential is given. Microb. Cell Fact. 9:82. doi: 10.1186/1475-2859-9-82

Vandesompele, J., De Preter, K., Pattyn, F., Poppe, B., Van Roy, N., De Paepem, A. et al. (2002). Accurate normalization of real-time quantitative RT-PCR 
data by geometric averaging of multiple internal control genes. Genome Biol. 3:research0034.1. doi: 10.1186/gb-2002-3-7-research0034

Wei, N., Xu, H., Kim, S. R., and Jin, Y. S. (2013). Deletion of FPS1, encoding aquaglyceroporin Fps1p, improves xylose fermentation by engineered Saccharomyces cerevisiae. Appl. Environ. Microbiol. 79, 3193-3201. doi: 10.1128/AEM.00490-13

Wimalasena, T. T., Greetham, D., Marvin, M. E., Liti, G., Chandelia, Y., Hart, A. et al. (2014). Phenotypic characterisation of Saccharomyces spp. yeast for tolerance to stresses encountered during fermentation of lignocellulosic residues to produce bioethanol. Microb. Cell Fact. 13:47. doi: 10.1186/14752859-13-47
Conflict of Interest Statement: The authors declare that the research was conducted in the absence of any commercial or financial relationships that could be construed as a potential conflict of interest.

Copyright () 2016 Pérez-Torrado, Oliveira, Zemančiková, Sychrová and Querol. This is an open-access article distributed under the terms of the Creative Commons Attribution License (CC BY). The use, distribution or reproduction in other forums is permitted, provided the original author(s) or licensor are credited and that the original publication in this journal is cited, in accordance with accepted academic practice. No use, distribution or reproduction is permitted which does not comply with these terms. 